\title{
The right technology for the right ventricular dysfunction: Are we facing the right way?
}

\author{
Francesco Formica, MD, and Stefano D’Alessandro, MD, FECTS
}

\footnotetext{
From the Department of Medicine and Surgery, Cardiac Surgery Unit, San Gerardo Hospital, University of Milano-Bicocca, Monza, Italy.

Disclosures: Authors have nothing to disclose with regard to commercial support.

Received for publication June 4, 2018; revisions received June 4, 2018; accepted for publication June 5, 2018; available ahead of print July 26, 2018

Address for reprints: Francesco Formica, MD, Clinica Cardiochirurgica Ospedale San Gerardo, ASST Monza Via G.B. Pergolesi 33, 20052, Monza (MB), Italy (E-mail: francesco_formica@ fastwebnet.it).

J Thorac Cardiovasc Surg 2018;156:2153-4

$0022-5223 / \$ 36.00$

Copyright (C) 2018 by The American Association for Thoracic Surgery

https://doi.org/10.1016/j.jtcvs.2018.06.008
}

Right ventricular failure (RVF) after left ventricular assist device (LVAD) implantation is a dramatic clinical condition with a very poor early and midterm outcome, as reported by the Interagency Registry for Mechanically Assisted Circulatory Support (INTERMACS) registry. ${ }^{1}$ Patients with severe RVF sometimes require a temporary right ventricular assist device (RVAD), with an incidence ranging from 5\% to $33 \% .^{2-5}$ Different technologies have been described to assist the right ventricle during RVF, such as extracorporeal membrane oxygenation (ECMO), surgical cannulation of the right atrium and the main pulmonary artery, ${ }^{6}$ or total percutaneous RVAD implantation through the femoral and the jugular veins. ${ }^{7}$ The limited experiences with these different RVAD models do not allow a wide application of these technologies.

In this issue of the Journal, Shehab and colleagues ${ }^{2}$ report on their experience of 23 patients receiving concomitant LVAD and a temporary RVAD represented by a venopulmonary extracorporeal life support (VPA-ECLS) with an integrated oxygenator. VPA-ECLS was instituted through an inflow cannula inserted in the femoral vein and an outflow cannula inserted into an 8-mm Dacron graft sutured end-to-side to the main pulmonary artery and tunneled through the precordium. The main aim in using the VPAECLS was to avoid surgery for the explant of the support to reduce the high mortality and morbidity rates in these fragile patients.

The authors compared the early and midterm outcome of these patients with those receiving initial biventricular (BiVAD) support $(\mathrm{n}=14)$ and isolated LVAD $(\mathrm{n}=75)$. As expected, patients who needed a right heart support (33\%) had a high level of comorbidities before LVAD implantation. Survival to discharge of isolated LVAD, VPA-ECLS, and BiVAD patients was $91 \%, 83 \%$, and $71 \%$, and 1 -year survival was $84 \%, 65 \%$, and $64 \%$, respectively. These results are quite encouraging despite a relatively greater incidence LVAD implant.

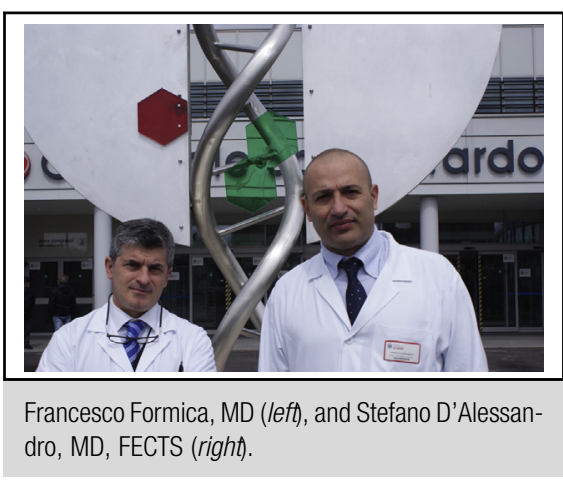

Central Message

The venopulmonary extracorporeal life support is a technique to temporarily assist a failed right heart after LVAD implant. The results are promising, but the oxygenator might limit a wider use.

See Article page 2143.

of adverse events (bleeding, infection, and renal dysfunction) in both the VPA-ECLS and BiVAD groups compared with the isolated LVAD subjects. In addition, the greater incidence of INTERMACS class 1 patients in the VPAECLS group (48\%) compared with subjects in the isolated LVAD group (19\%) represents further evidence of the validity of the VPA-ECLS for the treatment of RVF after

Some concerns may arise regarding the rationale to include the oxygenator. It is well-known that this device increases the risk of systemic inflammation, coagulopathy, and thromboembolism. Saeed and colleagues ${ }^{5}$ used this VPA-ECLS only in those patients with lung injury and ECMO support before LVAD insertion. The study of Shehab and colleagues ${ }^{2}$ did not demonstrate whether the oxygenator might negatively affect the outcome because they did not have a control group with a temporary RVAD without an oxygenator, although $43 \%$ of patients in the VPA-ECLS group were on ECMO before LVAD implant assuming that those patients had a severe lung injury. Lastly, as a reflection of data in a small patient cohort, the authors ${ }^{2}$ could not demonstrate a clearer clinical benefit of the VPAECLS approach compared with BiVAD in terms of early and midterm outcomes. 
Through this meticulous study, Shehab and colleagues ${ }^{2}$ have placed particular attention on the treatment of RVF, which remains an insidious complication after LVAD implantation that can be addressed with appropriate technologies.

\section{References}

1. Interagency Registry for Mechanically Assisted Circulatory Support (INTERMACS). Quarterly statistical report 2017 Q3. Implant and event dates: June 23, 2006 to September 30, 2017. Available at: https://www.uab.edu/medicine/ intermacs/images/Federal_Quarterly_Report/Federal_Partners_Report_2017_Q3. pdf. Accessed May 28, 2018.

2. Shehab S, Rao S, Macdonald P, Newton PJ, Spratt P, Jansz P, et al. Outcomes of venopulmonary arterial extracorporeal life support as temporary right ventricular support after left ventricular assist implantation. J Thorac Cardiovasc Surg. 2018; $156: 2143-52$.
3. Takeda K, Takayama H, Kalesan B, Uriel N, Colombo PC, Jorde UP, et al. Longterm outcome of patients on continuous-flow left ventricular assist device support. J Thorac Cardiovasc Surg. 2014;148:1606-14.

4. Kormos RL, Tueteberg JJ, Pagani FD, Russell SD, John R, Miller LW, et al. Right ventricular failure in patients with HeartMate II continuous-flow left ventricular assist device: incidence, risk factors and effect on outcomes. J Thorac Cardiovasc Surg. 2010;139:1316-24.

5. Saeed D, Maxhera B, Kamiya H, Lichtenberg A, Albert A. Alternative right ventricular assist device implantation technique for patients with perioperative right ventricular failure. J Thorac Cardiovasc Surg. 2015; 149:927-32.

6. Loforte A, Montalto A, Lilla della Monica P, Musumeci F. Simultaneous temporary CentriMag right ventricular assist device placement in HeartMate II left ventricular assist system recipients at high risk of right ventricular failure. Interact Cardiovasc Thorac Surg. 2010;10:847-50.

7. Takayama H, Naka Y, Kodali SK, Vincent JA, Addonizio LJ, Jorde UP, et al. A novel approach to percutaneous right-ventricular mechanical support. Eur J Cardiothorac Surg. 2012;41:423-6. 